Z Gerontol Geriat 2016 · 49:167

DOI 10.1007/s00391-015-1015-8

Published online: 15 January 2016

(c) Springer-Verlag Berlin Heidelberg 2015

CrossMark
Maria Magdalena Schreier ${ }^{1}$ Ulrike Bauer ${ }^{1}$ Jürgen Osterbrink ${ }^{1}$. Josef Niebauer ${ }^{2}$. Bernhard Iglseder ${ }^{3} \cdot$ Jens Reiss ${ }^{3}$

${ }^{1}$ Institute of Nursing Science and Practice, Paracelsus Medical University, Salzburg, Austria

2 Institute of preventive and rehabilitative Sports Medicine, Landeskrankenhaus, Salzburg, Austria

${ }^{3}$ Department of Geriatric Medicine, Christian Doppler Klinik, Paracelsus Medical University, Salzburg, Austria

\section{Erratum to: Fitness training for the old and frail}

\section{Effectiveness and impact on daily life coping and self-care abilities}

\author{
Erratum to: \\ Z Gerontol Geriat (2015) \\ DOI 10.1007/s00391-015-0966-0

\section{Methods} \\ Training program: collection and \\ analysis of quantitative data
}

Medical diagnoses, laboratory parameters and data on balance, risk of falls, etc. were collected from medical records. The statistical procedures included descriptive, univariate and bivariate analyses. Significance testing comparing various time points $(\mathrm{t} 0=$ baseline, $\mathrm{t} 4=$ end of training and $\mathrm{t} 5$ =follow-up) for the intervention and control groups were performed using IBM SPSS Statistics 18.

The following information is incorrect: Cronbach's alpha was set a priori at $5 \%$.

The correct statement is: Alpha was set a priori at $5 \%$.

The authors would like to apologise for this error.

\section{Corresponding address}

\section{M.M. Schreier}

Institute of Nursing Science and Practice,

Paracelsus Medical University

Salzburg

magdalena.schreier@pmu.ac.at

The online version of the original article can be found under doi:10.1007/s00391-015-0966-0 